Atıf için / For Citation: H. Özkan, "N-Alkillenmiş Tetrazol Türevi Bileşiklerin Absorpsiyon, Dağılım, Metabolizma ve Atılım (ADME) Özelliklerinin Araştırılması",, Süleyman Demirel Üniversitesi Fen Edebiyat Fakültesi Fen Dergisi, 14(2), 384-394, 2019.

\title{
$N$-Alkillenmiş Tetrazol Türevi Bileşiklerin Absorpsiyon, Dağılım, Metabolizma ve Atılım (ADME) Özelliklerinin Araştırılması
}

\author{
Hamdi ÖZKAN* \\ Gazi Üniversitesi, Fen Fakültesi, Kimya Bölümü, 06500, Ankara, Türkiye \\ *yazışlan yazar e-posta: hozkan@gazi.edu.tr
}

(Alınış / Received: 08.10.2019, Kabul / Accepted: 12.11.2019, Yayımlanma / Published: 30.11.2019)

Özet: Tetrazoller heterosiklik bileşiklerdir. Tetrazol halkası içeren bileşikler, antiviral, antibakteriyel, antifungal, antialerjik, antiülser, antikonvülsan, antiinflamatuar, antitüberküloz gibi farmakolojik etkinliklerinden dolayı ilaç sentezinde sıklıkla kullanılır. Tetrazol türevi bir ilaç olan Losartan yüksek tansiyon, Tomelukast astım tedavisinde kullanılır. Bu çalışmada, aromatik halkalar içeren $\mathrm{N}$-alkillenmiş tetrazol türevleri sentezlendi. Sentezlenen bileşiklerin yapıları spektroskopik yöntemlerle aydınlatıldı. Aynı zamanda, sentezlenen moleküllerin ADME (absorpsiyon, dağılım, metabolizma ve atılım) özellikleri in silico olarak incelendi. Teorik olarak, bileşik $\mathbf{4 a}, \mathbf{4 b}$ ve $\mathbf{4 c}$ 'nin ince bağırsağından absorpsiyon yüzdeleri hesaplandı ve sırasıyla 93,95, 93,95 ve 90,77 gibi çok yüksek değerler bulundu. Tetrazol halkasını içeren bu bileşikler, merkezi sinir sistemini etkileyecek moleküller için önemli bir özellik olan kan beyin bariyerini kolayca geçerler. Bu nedenle, bu bileşiklerin antidepresan ilaçların sentezi için iyi adaylar oldukları söylenebilir.

Anahtar kelimeler: Heterosiklik Bileşik, Tetrazol, ADME, Farmakokinetik.

\section{$\mathrm{N}$-Alkylated Tetrazole Derivative Compounds and Investigation of Absorption, Distribution, Metabolism and Excretion (ADME) Properties}

\begin{abstract}
Tetrazoles are heterocyclic compounds. The compounds containing the tetrazole ring are frequently used in drug synthesis due to their pharmacological activities such as antiviral, antibacterial, antifungal, antiallergic, antiulcer, anticonvulsant, anti-inflammatory, antituberculosis. Tetrazole derivated drug Losartan is used to treat high blood pressure, Tomelukast asthma. In this study, $N$-alkylated tetrazole derivatives containing substituted aromatic rings were synthesized. The structures of the synthesized compounds were determined by spectroscopic methods. At the same time, ADME (absorption, distribution, metabolism and excretion) properties of the synthesized molecules were investigated as silico. Theoretically, the percentages of absorption from the small intestine of compounds $4 \mathbf{a}, 4 \mathbf{b}$ and $\mathbf{4 c}$ were calculated and very high values were found, such as 93.95, 93.95 and 90.77, respectively. These compounds containing the tetrazole ring easily cross the blood brain barrier, which is an important property for molecules that will affect the central nervous system. Therefore, it can be said that these compounds are good candidates for the synthesis of antidepressant drugs.
\end{abstract}

Key words: Heterocyclic Compounds, Tetrazole, ADME, Pharmacokinetic. 


\section{Giriş}

Tetrazoller, bir karbon atomu ve dört azot atomundan oluşmuş 5 üyeli aromatik halkalardır.

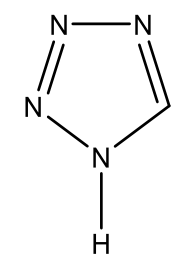

Şekil 1. Tetrazol bileşiğinin molekül yapısı

Tetrazol, içerdiği üç tane tersiyer azot atomunun indüktif olarak elektron çekmesinden dolayı zayıf asidik özellik gösterir $\left(\mathrm{pK}_{\mathrm{a}}=4,76\right)$. 5-Sübstitüe- $1 H$-tetrazoller uzun süredir biyolojik aktif moleküllerdeki karboksilik asitlerin $\left(\mathrm{RCO}_{2} \mathrm{H}\right)$ biyoizosteri olarak görev yapmaktadır. Biyoizoster kavramı, benzer biyolojik ve fizikokimyasal özelliğe sahip fonksiyonel grupların değiştirilebileceğini ifade etmektedir. Ayrıca, bir biyoizoster aynı sterik ve elektronik karaktere sahip olabilir. Tetrazoller, özellikle tarım, ilaç, eczacılık ve kimya endüstrilerinde yaygın olarak kullanılan heterosiklik bileşiklerdir. 20. yüzyılın ortalarından sonra, tetrazol türevi bileşiklerin eczacılıkta, korozyon inhibitörlerinde, patlayıcı madde yapımında [1] ve fotoğraf ve bilgi kayıt sistemlerinde [2] kullanılması bu bileşiklere olan ilgiyi arttırdı. Tetrazollerin biyolojik olarak karboksilik asit grubuna eşdeğer olduğu kabul edilir ve tıbbi kimya alanında [3] tetrazoller üzerinde kapsamlı çalışmalar yapılmıştır. Tetrazol türevleri, biyolojik önemi nedeniyle tarım, biyokimya ve farmakolojide kapsamlı bir şekilde araştırılmıştır [1]. Tetrazoller kanser ve AIDS tedavisinde de kullanılmaktadır [4, 5]. Tetrazol türevleri farmakolojik etkinliğe sahip olması nedeniyle ilaç sentezinde sıkça kullanılmaktadır [6, 7]. Tetrazol halkasını içeren bileşikler, antiviral, antibakteriyel, antifungal, antialerjik, antiülcer, antikonvülsan, antienflamatuar, antitubüler gibi farmakolojik etkinlikleri bulunmaktadır. Yüksek tansiyon tedavisinde kullanılabilen Losartan adlı bir tetrazol türevi ilaç tetrazol halkası içermektedir. Çalışma grubumuz daha önce birçok tetrazol bileşiğinin sentezini ve biyolojik aktivitelerini (antibakteriyel ve antifungal) bildirmiştir [8]. Tetrazoller biyolojik olarak aktif bileşiklerdir.

Farmakokinetik terimi ilk defa 1953 yılında Prof. Dr. Friedrich Hartmut Dost tarafindan yazılan "Der Blutspiegel (Kan Profili)" adlı kitapta geçmektedir [9]. Aynı zamanda Prof. Dost 1968'de "Grundlagen der Pharmakokinetik (Farmakokinetiğin Temelleri)" adında bir kitap yayınlamıştır [10]. Günümüzde kemoinformatik bilgisayar programları, kimyasal bileşiklerin moleküler yapısından metabolizma üzerindeki muhtemel etkileri ve onların ilaç olarak kullanılıp kullanılamayacağı konusunda deneysel çalışmalar yapmadan bizlere önemli bilgiler verilmektedir. Dünyada her yıl binlerce molekül sentezlenmektedir. Bunların laboratuvar ortamındaki biyoaktivite testleri çok yüksek maliyetler tutmaktadır. $\mathrm{Bu}$ nedenle, ADME çalışmaları bileşiklerin ilaç olabilme potansiyellerinin anlaşılmasında çok önemlidir [11]. Bu amaçla, $N$-alkillenmiş tetrazol halkaları içeren benzen türevlerini sentezlemeye karar verdik. Toplam 3 bileşik sentezlendi. Sentezlenen bileşiklerin yapıları spektroskopik yöntemlerle (FTIR, ${ }^{1} \mathrm{H}$ NMR, ${ }^{13} \mathrm{C}$ - APT -NMR) aydınlatıldı. Daha sonra sentezlenen bileşiklerin absorpsiyon, dağılım, metabolizma ve atılım (ADME) çalışmaları gerçekleştirildi. 


\section{Materyal ve Metot}

Sentezde kullanılan tüm reaktifler ve çözücüler Merck ve Aldrich'ten satın alındı ve saflaştırılmadan kullanıldı. Sentezlenen bileşiklerin erime noktaları Electrothermal 9100 cihazı ile tayin edildi. NMR analizleri, Bruker 300 ve $400 \mathrm{MHz}$ Spektrometre cihazları ile yapıldı ( ${ }^{1} \mathrm{H}-\mathrm{NMR}, 300-400 \mathrm{MHz} ;{ }^{13} \mathrm{C}-\mathrm{NMR}, 75-100 \mathrm{MHz}$, kimyasal kayma değerleri $\delta$ ppm türünden verilmiştir). İç standart madde olarak tetrametilsilan (TMS), çözücü olarak kloroform- $d\left(\mathrm{CDCl}_{3}\right)$ kullanıldı. Sentezlenen bileşiklerin element analizleri Thermo Scientific Flash 2000 element analizi cihazı kullanılarak gerçekleştirildi. ATRFTIR spektrumları Thermo Nicolat 6700 ATR cihazında çekilmiştir. Sentez çalışmaları sırasında, tepkimeyi izlemek ve ürünün saflığı kontrol etmek amaciyla İnce Tabaka Kromatografisinden (İTK) yararlanıldı. Uygulamada Silufol UV-254 plakaları (Merck) kullanılmış ve noktaların belirlenmesi için 254 ve $366 \mathrm{~nm}$ dalga boyundaki UV 1şı̆̆ından faydalanıldı. Ürünler Flash Kromatografi (Buchi C-601) cihazı yardımıyla silika jel $\left(60 \mathrm{~F}_{254} / 70-230\right.$ mesh) üzerinden kolonda saflaştırıldı.<smiles>[R]c1ccc(C=O)cc1</smiles>

1

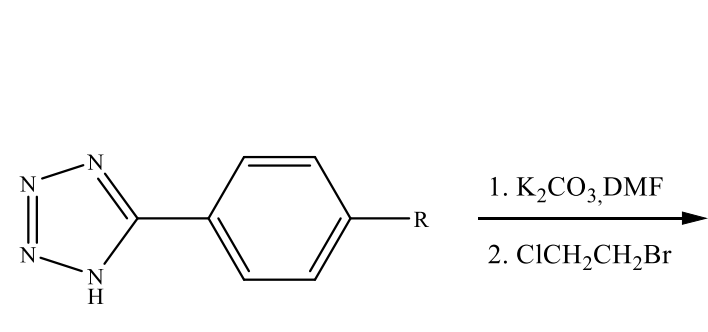

3

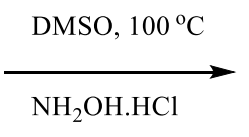<smiles>[R]c1ccc(C#N)cc1</smiles>

2

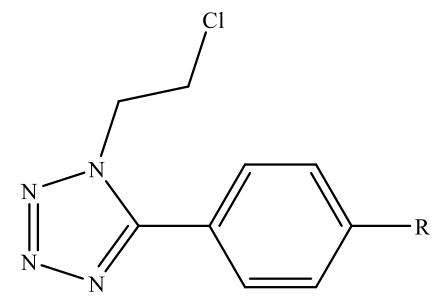

R: $4 a:-F$
4b: $-\mathrm{Cl}$
4c: $-\mathrm{OCH}_{3}$
1. $\mathrm{NaN}_{3}, \mathrm{Et}_{3} \mathrm{~N} . \mathrm{HCl}$,

Toluen

2. $\mathrm{H}_{3} \mathrm{O}^{+}$

Şekil 2. 1-(2-Kloroetil)-5-(4-sübstitüefenil)-1H-tetrazol türevi bileşiklerin sentezi

\subsection{4-Florobenzonitril Bileşiğinin Sentezi (2a)}

4-Florobenzaldehit $(0,62 \mathrm{~g}, 5 \mathrm{mmol}$, ) iki boyunlu bir balona alınarak üzerine $30 \mathrm{~mL}$ DMSO ve hidroksilamin hidroklorür $(0,643 \mathrm{~g}, 9,25 \mathrm{mmol})$ eklendi. Geri soğutucu altında $100^{\circ} \mathrm{C}$ 'ta 1 saat karıştırıldı. Bu süre sonunda oda sıcaklığına soğutulan karışım üzerine soğuk su eklenerek beyaz renkli 4-florobenzonitril'in (2a) çökmesi sağlandı ve süzme işlemi yapıldı. Elde edilen katı dietil eterden kristallendirildi. Sentezlenen bileşik literatürde bilinen madde olduğu için sadece erime noktasına bakıldı.

Verim \% 87, EN: $30-32{ }^{\circ} \mathrm{C}$, Lit, EN: $34-35^{\circ} \mathrm{C}$ [12].

\subsection{4-Klorobenzonitril Bileşiğinin Sentezi (2b)}

2a bileşiğinin sentezinde kullanılan yöntem uygulandı. 0,703 g 1b bileşiği ( $5 \mathrm{mmol}$ ), 0,643 g hidroksilamin hidroklorür $(9,25 \mathrm{mmol}) 30 \mathrm{~mL}$ DMSO içinde çözüldü. Tepkime sonunda elde edilen beyaz renkli 4-klorobenzonitril (2a) katıs1 dietil eterden kristellendirildi. Verim \% 85, EN: 86-88 ${ }^{\circ} \mathrm{C}$, Lit, EN: $87-89{ }^{\circ} \mathrm{C}$ [13]. 


\subsection{4-Metoksibenzonitril Bileşiğinin Sentezi (2c)}

2a bileşiğinin sentezinde kullanılan yöntem uygulandı. 0,681 g 1c bileşiği (5 mmol), $0,643 \mathrm{~g}$ hidroksilamin hidroklorür $(9,25 \mathrm{mmol}) 30 \mathrm{~mL}$ DMSO içinde çözüldü. Tepkime sonunda elde edilen beyaz renkli 4-metoksibenzonitril (2c) katısı dietil eterden kristellendirildi. Verim \% 82, EN: $55-57{ }^{\circ} \mathrm{C}$, Lit, EN: $56-57{ }^{\circ} \mathrm{C}$ [14].

\subsection{5-(4-Florofenil)-1H-Tetrazol Bileşiğinin Sentezi (3a)}

İki boyunlu balona trietilamin hidroklorür $(1,24 \mathrm{~g}, 9 \mathrm{mmol})$ ve $20 \mathrm{~mL}$ toluen eklendi. Üzerine önce yavaş yavaş sodyum azür $(0,586 \mathrm{~g}, 9 \mathrm{mmol})$ ardından $10 \mathrm{~mL}$ toluende çözülmüş 4-florobenzonitril (2a) (0,363 g, 3 mmol) çözeltisi azar azar eklendi. Karışım $100^{\circ} \mathrm{C}$ 'da 16 saat karıştırıldı. Bu süre sonunda İTK ile kontol edilerek oda sıcaklığına soğumaya bırakıldı. Karışım, 3x30 mL su ile ekstrakte edildi. Su fazı seyreltik $\mathrm{HCl}$ çözeltisiyle pH:2-3 olana kadar asitlendirildi. Çöken beyaz renkli katı (3a) süzüldü ve etil asetat-heksan çözücü çifti ile kristallendirildi. Verim \% 82, EN: $208-210{ }^{\circ} \mathrm{C}$, Lit EN: 208-212 ${ }^{\circ} \mathrm{C}[15]$.

\subsection{5-(4-Klorofenil)-1H-Tetrazol Bileşiğinin Sentezi (3b)}

3a bileşiğinin sentezinde kullanılan yöntem uygulanmıştır. 1,24 g trietilamin hidroklorür (9 mmol), 0,586 g sodyum azürün $(9 \mathrm{mmol}) 20 \mathrm{~mL}$ toluendeki çözeltisine, $10 \mathrm{~mL}$ toluende çözülmüş, 0,413 g (3 mmol) 4-klorobenzonitril (2b) eklendi. Elde edilen beyaz renkli katı (3b) etil asetat-heksan çözücü çifti ile kristallendirildi. Verim \% 80, EN: 250$252{ }^{\circ} \mathrm{C}$, Lit EN: $252-254{ }^{\circ} \mathrm{C}$ [12].

\subsection{5-(4-Metoksifenil)-1H-Tetrazol Bileşiğinin Sentezi (3c)}

3a bileşiğinin sentezinde kullanılan yöntem uygulanmıştır. 9 mmol trietilamin hidroklorür (1,24 g), $9 \mathrm{mmol}$, sodyum azürün $(0,586 \mathrm{~g}) 20 \mathrm{~mL}$ toluendeki çözeltisine, $10 \mathrm{~mL}$ toluende çözülmüş, $3 \mathrm{mmol}(0,400 \mathrm{~g})$ 4-metoksibenzonitril (2c) eklendi. Elde edilen beyaz renkli katı (3c) etil asetat-heksan çözücü çifti ile kristallendirildi.

Verim \% 81, EN: $227-229{ }^{\circ} \mathrm{C}$, Lit. EN:229-230 ${ }^{\circ} \mathrm{C}$ [16].

\subsection{1-(2-Kloroetil)-5-(4-Florofenil)-1H-Tetrazol Bileşiğinin Sentezi (4a)}

50 mL'lik balona 5-(4-florofenil)- $1 H$-tetrazol (3a) $(0,328 \mathrm{~g}, 2 \mathrm{mmol})$ alındı ve üzerine $15 \mathrm{~mL}$ DMF ve potasyum karbonat $(0,553 \mathrm{~g}, 4 \mathrm{mmol}$, ) eklendi ve oda sicaklığında 1 saat karıştırıldı. Daha sonra üzerine 1-bromo-2-kloroetan $(0,24 \mathrm{~mL}, 3 \mathrm{mmol}$,) eklenerek oda sıcaklığında 16 saat karıştırıldı. Bu süre sonunda karışım İTK ile kontrol edilerek tepkime sonlandırıldı. Karışım buzlu su-etil asetat $(5 \times 25 \mathrm{~mL})$ ile ekstrakte edildi, organik faz magnezyum sülfat ile kurutuldu, çözücüsü döner buharlaştırıcıda uzaklaştırıldı. Geriye kalan katı karışımı heksan:etil asetat (4:1) çözücü çifti kullanılarak kolon kromatografisi yardımıyla birbirinden ayrıldı Elde edilen beyaz renkli katının (4a) erime noktas1, 58-60 ${ }^{\circ} \mathrm{C}$ 'dir. Verim \% 52, EN:58-60 ${ }^{\circ} \mathrm{C}$, Lit. EN: $60-62{ }^{\circ} \mathrm{C}$ [15]. IR $\left(\mathrm{ATR}, v_{\max } / \mathrm{cm}^{-1}\right): 3040(\mathrm{Ar}, \mathrm{C}=\mathrm{CH}), 2875(\mathrm{Al}, \mathrm{CH}), 1694(\mathrm{C}=\mathrm{N}), 1597,1498(\mathrm{Al}$, $\mathrm{C}=\mathrm{CH}) .{ }^{1} \mathrm{H}-\mathrm{NMR}\left(400 \mathrm{MHz}, \mathrm{CDCl}_{3}\right): 8,30-8,10(\mathrm{~m}, 2 \mathrm{H}), 7,30-7,10(\mathrm{~m}, 2 \mathrm{H}), 5,10$ 4,90 (m, 2H), 4,20-4,10 (m, 2H). ${ }^{13} \mathrm{C}-\mathrm{NMR}$ (100 MHz, $\left.\mathrm{CDCl}_{3}\right): 165,3,164,6,128,9$, 123,4, 116,1, 54,1, 40,7. Element Analizi Teorik $\left(\mathrm{C}_{9} \mathrm{H}_{8} \mathrm{ClFN}_{4}\right): \mathrm{C}, 47,70 ; \mathrm{H}, 3,56 ; \mathrm{N}$, 24,72; Deneysel: C, 47,81; H, 3,63; N, 23,31. 
4a bileşiğinin sentezinde kullanılan yöntem uygulanmıştır. 2 mmol 5-(4-klorofenil)- $1 H$ tetrazol (3b) (0,361 g), $4 \mathrm{mmol}$ potasyum karbonat $(0,553 \mathrm{~g}), 3 \mathrm{mmol}$ 1-bromo-2kloroetan $(0,24 \mathrm{~mL})$ bileşiklerinin $15 \mathrm{~mL}$ DMF içerisindeki çözeltisinin tepkimesinden elde edilen katı karışımı heksan:etil asetat (4:1) çözücü çifti kullanılarak kolon kromatografisi yardımıyla birbirinden ayrıldı. Verim \% 53, EN: 96-98 ${ }^{\circ} \mathrm{C}$, IR (ATR, $\left.v_{\max } / \mathrm{cm}^{-1}\right): 3030(\mathrm{Ar}, \mathrm{C}=\mathrm{CH}), 2870(\mathrm{Al}, \mathrm{CH}), 1690(\mathrm{C}=\mathrm{N}), 1595,1500(\mathrm{Al}, \mathrm{C}=\mathrm{CH}) .{ }^{1} \mathrm{H}-$ NMR (300 MHz, CDCl $\left.{ }_{3}\right): 8,15-8,05(\mathrm{~m}, 2 \mathrm{H}), 7,55-7,45(\mathrm{~m}, 2 \mathrm{H}), 5,0(\mathrm{t}, 2 \mathrm{H}), 4,1$ (t, 2H). ${ }^{13} \mathrm{C}$ APT-NMR (75 MHz, $\mathrm{CDCl}_{3}$ ): 164,6, 136,7, 129,2, 128,2, 125,6, 54,1, 40,6. Element Analizi Teorik $\left(\mathrm{C}_{9} \mathrm{H}_{8} \mathrm{Cl}_{2} \mathrm{~N}_{4}\right)$ : C, 44,47; H, 3,32; N, 23,05; Deneysel: C, 45,57; H, 3,68; N, 20,90.

\subsection{1-(2-Kloroetil)-5-(4-Metoksifenil)-1H-Tetrazol Bileşiğinin Sentezi (4c)}

4a bileşiğinin sentezinde kullanılan yöntem uygulanmıştır. 2 mmol 5-(4-metoksifenil)$1 H$-tetrazol (3c) $(0,352 \mathrm{~g}), 4 \mathrm{mmol}$ potasyum karbonat $(0,553 \mathrm{~g}), 3 \mathrm{mmol} 1$-bromo-2kloroetan $(0,24 \mathrm{~mL})$ bileşiklerinin $15 \mathrm{~mL}$ DMF içerisindeki çözeltisinin tepkimesinden elde edilen katı karışımı heksan:etil asetat (4:1) çözücü çifti kullanılarak kolon kromatografisi yardımıyla birbirinden ayrıld1. Verim \% 51, EN: 58-61 ${ }^{\circ} \mathrm{C}$, IR (ATR, $\left.v_{\max } / \mathrm{cm}^{-1}\right): 3035(\mathrm{Ar}, \mathrm{C}=\mathrm{CH}), 2880(\mathrm{Al}, \mathrm{CH}), 1690(\mathrm{C}=\mathrm{N}), 1595,1490(\mathrm{Al}, \mathrm{C}=\mathrm{CH})$, 1250, 1050 (C-O). ${ }^{1} \mathrm{H}-\mathrm{NMR}\left(400 \mathrm{MHz}, \mathrm{CDCl}_{3}\right): 8,20-8,10$ (m, 2H), 7,10-6,90 (m, 2H), 5,00-4,90 (t, 2H), 4,15-4,05 (m, 2H), 3,80 (s, 3H). ${ }^{13} \mathrm{C}-\mathrm{NMR}\left(100 \mathrm{MHz}, \mathrm{CDCl}_{3}\right): 164,3$, $161,3,128,4,119,7,114,3,55,3,54,0,40,7$. Element Analizi Teorik $\left(\mathrm{C}_{10} \mathrm{H}_{11} \mathrm{ClN}{ }_{4} \mathrm{O}\right): \mathrm{C}$, 50,32; H, 4,65; N, 23,47; Deneysel: C, 51,13; H, 4,84; N, 21,52.

In silico ADME çalışmaları, bileşiklerin fizikokimyasal, farmakokinetik, lipofilite ve suda çözünürlük gibi özelliklerini belirlemek için SwissADME web sitesi kullanılarak yapıldı [17]. Bileşiklerin ince bağırsaktan \% absopsiyonu \% ABS =109-0,345xTPSA formülü kullanılarak hesaplandı [18].

\section{Sonuç ve Yorum}

Çalışmamızda önce sübstitüe aldehit türevleri alındı ve benzonitril türevlerine dönüştürülmüştür. Sentezlenen benzonitril türevleri dietil eterde kristellendirildi ve erime noktaları ve FTIR spektrumları kontrol edildi. Erime noktaları ve FTIR spektrumları literatür verileriyle uyum içerisindedir. Benzaldehit türevlerinde $\mathrm{C}=\mathrm{O}$ gerilme titreşimi $1700 \mathrm{~cm}^{-1}$ de görülmektedir. Benzonitril türevlerinde FTIR spektrumunda $1700 \mathrm{~cm}^{-1}$ de görülen band kaybolmaktadır. Aynı zamanda $2250 \mathrm{~cm}^{-1}$ de -CN gerilme titreşimi gözlenmektedir. Daha sonra sübstitüe fenil tetrazol türevleri sentezlendi. Tetrazol türevleri etil asetat-heksan çözücü çiftinden kristallendirildi. Sentezlenen tetrazol türevlerinin erime noktaları ve ${ }^{1} \mathrm{H}-\mathrm{NMR}$ spektrumları literatür verileriyle uyum içerisindedir. $2500-3500 \mathrm{~cm}^{-1}$ aralığındaki yayvan band tetrazol halkasında bulunan $\mathrm{N}-\mathrm{H}$ gerilme titreşiminden kaynaklanmaktadır. Tetrazol halkasındaki N-H protonuna ait pik ${ }^{1} \mathrm{H}-\mathrm{NMR}$ spektrumunda ( $\delta$ ) 13,38-11,49 ppm arasında birli ve yayvan olarak çıkmaktadır. Tetrazol halkasına etilklorür grubu bağlandığında elde edilen alkil tetrazol bileşiğinin ${ }^{1} \mathrm{H}-\mathrm{NMR}$ spektrumunda bu bölgedeki pik kaybolmaktadır. Tetrazoller başlıca $1 H$ ve $2 H$-tetrazoller olarak belirtilirler ve nasıl numaralandırıldıkları Şekil 3 te gösterilmiştir $[19,20]$. 


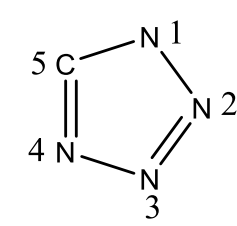

$$
7
$$

$1 H$-Tetrazol
Sekil 3. $1 H$ ve $2 H$-tetrazol bilesik

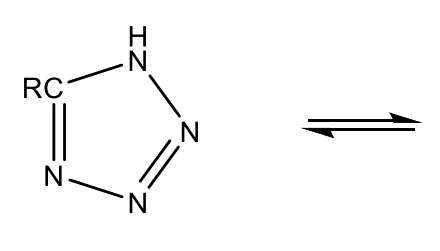

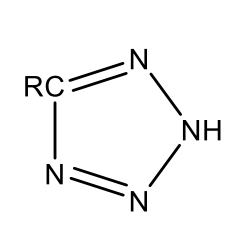

$2 H$-Tetrazol

Şekil 3. $1 H$ ve $2 H$-tetrazol bileşiklerinin tautomerik dengesi

1-Bromo-2-kloroetan bileşiğinin tetrazol halkasındaki N-H protonu ile yerdeğiştirme tepkimesinde hem 1-alkil tetrazol hem de 2-alkil tetrazol türevleri oluşmaktadır. Tepkime sonucunda 1-alkil ve 2-alkil bileşiklerinin bulunduğu karışıma kolon kromatografisi uygulandı. 1-alkil bileşiği saf olarak elde edilirken, 2-alkil bileşiği kolondan alınamadi. Ana ürün 1-alkil tetrazoldür. 1-Alkil tetrazol türevleri izole edilmiş ve spektroskopik yöntemlerle yapıları aydınlatılmıştır. Alkil tetrazol türevlerinde 1numaralı $\mathrm{N}$ atomuna bağlı olan $\mathrm{CH}_{3}$ grubundaki protonların ve karbonların kimyasal kayma değerleri ile 2-numaralı $\mathrm{N}$ atomuna bağlı olan $\mathrm{CH}_{3}$ grubundaki protonların ve karbonların kimyasal kayma değerleri birbirinden farklıdır [21, 22].

Tablo 1. Sübstitüe $1 H$ ve $2 H$-Tetrazol Bileşiklerinin Kimyasal Kayma Değerleri

\begin{tabular}{|c|c|c|}
\hline & 1-İzomer & 2-İzomer \\
\hline $\begin{array}{l}{ }^{1} \mathrm{H}-\mathrm{NMR} \text { Spektrumu } \\
\text { Kimyasal kayma }(\delta) \text { ppm: }\end{array}$ & $\mathrm{H}\left(\mathrm{CH}_{3}\right): 5,73$ & $\mathrm{H}\left(\mathrm{CH}_{3}\right): 5,54$ \\
\hline $\begin{array}{l}{ }^{13} \text { C-NMR Spektrumu } \\
\text { Kimyasal kayma }(\delta) \text { ppm: }\end{array}$ & $\mathrm{C}\left(\mathrm{CH}_{3}\right): 35$ & $\mathrm{C}\left(\mathrm{CH}_{3}\right): 39,4$ \\
\hline
\end{tabular}

Sentezlenen $\mathbf{4 a}, \mathbf{4 b}$ ve $\mathbf{4 c}$ bileşiklerinin yapıları spektroskopik (FTIR, ${ }^{1} \mathrm{H}-\mathrm{NMR},{ }^{13} \mathrm{C}-$ NMR ve element analizi) yöntemlerle aydınlatılmıştır. Sonuçlar literatür verileriyle uyum içerisindedir. $\mathbf{4 b}$ ve $\mathbf{4 c}$ bileşiklerinin literatürde erime noktaları verilmemiştir [15]. Renksiz berrak sıvılar olarak tanımlanmıştır. Sentez sonucunda elde edilen $\mathbf{4 b}$ ve 4c bileşikleri evaporatörde çözücüsü uzaklaştırıldığında sıvı haldedir, ancak bir süre beklendiğinde katı hale geçmektedirler. Ayrıca literatürde $\mathbf{4 a}, \mathbf{4 b}$ ve $\mathbf{4 c}$ bileşiklerine ait sadece erime noktası ve ${ }^{1} \mathrm{H}$-NMR verileri bulunmaktadır. FTIR, ${ }^{13} \mathrm{C}$-NMR ve element analizi verileri bulunmamaktadır. Her üç bileşikte tetrazol halkası, para sübstitüe aromatik halka ve tetrazol halkasına bağlı etil klorür grubu içermektedir. Bu nedenle FTIR spektrumunda yaklaşık $3040 \mathrm{~cm}^{-1}$ de aromatik $-\mathrm{CH}$ gerilme band, $1690 \mathrm{~cm}^{-1}$ 'de tetrazol halkasındaki $\mathrm{C}=\mathrm{N}$ gerilme bandı, yaklaşık $2950 \mathrm{~cm}^{-1}$ de alifatik $-\mathrm{CH}$ gerilme bandı gözlemlenmektedir. Bileşiklere ait ${ }^{1} \mathrm{H}$-NMR spektrumları incelendiğinde sonuçlar sentezlenen bileşikler ile uyum içerisindedir. Aromatik halka para sübstitüe olduğu için aromatik halkadaki özdeş olmayan hidrojenlere ait pikler 7,50-8,10 ppm civarında dubletin-dubleti (ikilinin ikilisi) şeklinde çıkmaktadır. Alifatik $\mathrm{CH}_{2}$ pikleri ise yaklaşık 4,10-5,00 civarında çıkmaktadır. Bu sonuçlar tetrazol halkasının 1 konumundan alkillendiğini göstermektedir. Tetrazol halkasındaki N-H protonuna ait 13,38-11,49 ppm civarında çıkan pikin kaybolması tetrazol halkasının alkillendiğini kanıtlamaktadır. 4a ve $\mathbf{4 b}$ bileşiklerinin yapıları incelendiğinde kimyasal çevresi farklı (özdeş olmayan) 7 tane, $\mathbf{4 c}$ bileşiğinde ise 8 farklı karbon atomunun bulunduğu görülmektedir. $4 \mathbf{a}$ ve $\mathbf{4 b}$ 
bileşiklerinin ${ }^{13} \mathrm{C}$-NMR APT spektrumlarında 7 farklı pik, 4c bileşiğinin ${ }^{13} \mathrm{C}-\mathrm{NMR}$ APT spektrumunda 8 farklı gözlemlenmektedir. Pozitif genlikte; $-\mathrm{H}$ içermeyen karbonlar ve $-\mathrm{CH}_{2}$ karbonları, negatif genlikte; $-\mathrm{CH}$ karbonları ve $-\mathrm{CH}_{3}$ karbonları görülmektedir. 4a bileşiğinde 165,3, 4b bileşiğinde 136,7, 4c bileşiğinde 161,3 ppm de gözlemlenen pikler aromatik halkadaki $\mathrm{F}, \mathrm{Cl}$ ve $\mathrm{OCH}_{3}$ gruplarının bağlı olduğu hidrojen içermeyen karbonlara ait piklerdir. 4a bileşiğinde 164,6, 4b bileşiğinde 164,6, 4c bileşiğinde 164,3 ppm de gözlemlenen pikler tetrazol halkasındaki hidrojen içermeyen karbonlara ait piklerdir. 4a bileşiğinde 128,9, $4 \mathbf{b}$ bileşiğinde 129,2, 4c bileşiğinde 128,4 ppm de gözlemlenen pikler aromatik halkayı tetrazol halkasına bağlayan ve hidrojen içermeyen karbon atomlarına ait piklerdir. ${ }^{13} \mathrm{C}-\mathrm{NMR}$ spektrumunda yaklaşık 40,6-54,0 ppm civarında çıkan pikler tetrazol halkasındaki etil klorür grubunda yer alan $\mathrm{CH}_{2}$ gruplarındaki karbonlara ait piklerdir. 54,0 ppm civarında çıkan pik tetrazol halkasına bağlı olan $\mathrm{CH}_{2}$ grubuna, 40,6 ppm civarında çıkan pik $\mathrm{Cl}$ atomuna bağlı olan $\mathrm{CH}_{2}$ grubuna ait olan piktir.

Bileşiklerin deneysel element analiz sonuçları teorik olarak hesaplanan değerlerle uyum içerindedir. $\mathrm{Bu}$ sonuçlar 1şı̆̆ında sentezlenen bileşikler için öngörülen yapılarla, deneysel olarak elde edilen bileşikler örtüşmektedir.

Sentezlenen bileşiklerin ADME çalışmalarının sonuçları Tablo 2'de gösterilmiştir. Suda çözünürlük kriterleri; çözünmez $<-10<$ zayıf $<-6<$ orta $<-4<$ çözünür $<-2<$ çok $<0<$ çok iyi olarak tanımlanmaktadır. Tablo 2'deki Log S (ESOL: Estimating Aqueous Solubility) değerleri dikkate alındığında yeni sentezlenen moleküller suda çözünmektedir. Bileşiklerin ince bağırsaktan emilim yüzdeleri $\mathbf{4 a}, \mathbf{4 b}$ ve $\mathbf{4 c}$ molekülleri için sırayla 93,95, 93,95 ve 90,77 gibi çok yüksek oranlarda hesaplanmıştır. Tetrazol yapısındaki bileşiklerin serotonin salınımını aktive ettiği çeşitli çalışmalarda rapor edilmiştir [23, 24]. Tetrazol halkası içeren bu bileşikler, merkezi sinir sistemi üzerinde etkili olacak moleküller için önemli bir özellik olan kan beyin bariyerini de rahatlıkla geçmektedir. Bu nedenle, bu bileşiklerin antidepresan ilaçların sentezi için iyi bir aday olduğu söylenebilir. SwissADME web sayfası, bileşiklerin Lipinski, Ghose, Veber, Egan ve Muegge kuralları olarak bilinen 5 farklı değerlendirme ölçeğine göre ilaç olarak oral uygulama için uygunluklarını değerlendirir [25-29]. Lipofiliklik ve çözünürlük, bir ilacın emiliminde kilit moleküler özelliklerdir. Farmakokinetik parametrelere, ilk olarak 1997 yılında, Lipinski ve arkadaşlarının Faz II klinik çalışmaları için onaylanan Dünya İlaç İndeksi (WDI) veri tabanındaki 2245 ilacın fizikokimyasal özelliklerinin araştırılmasına dayanan beş kuralı (Ro5) yayınladıkları zaman teorik olarak yaklaşılmış oldu [25]. Bir ilacın oral biyoyararlanımını tahmin etmek için kullanılan bu kural, test edilen bileşiklerin fiziko kimyasal özelliklerine dayanır:

1. $\mathrm{M} \log \mathrm{P} \leq 5$.

2. Moleküler ağırlık $(\mathrm{MW}) \leq 500 \mathrm{~g} / \mathrm{mol}$.

3. Hidrojen bağı alıcı sayısı (HBA) (toplam $\mathrm{N}$ ve $\mathrm{O}$ atomlarının) $\leq 10$. Hidrojen bağ verici sayısı (HBD) (toplamı $\mathrm{OH}$ ve $\mathrm{NH}$ grupları) $\leq 5$.

4. Dönebilen bağ sayısı (nRotb) $\leq 10$.

5. Kutuplaşmış yüzey alanı (TPSA) $\AA^{2}<140 \AA^{2}$

Online olarak alınan sonuçlara göre sentezlenen bileşikler bu kriterleri karşılamaktadır. Sitokrom P450 (CYP) ilaçların vücuttan atılmak amacıyla parçalanmasında önemli rol oynayan enzimlerdir [30]. Onların inhibisyonu ilaçların vücuttan atılımının gecikmesine yol açmaktadır [31]. Bu sistemin beş temel enzimi (CYP1A2, CYP2C19, CYP2C9, CYP2D6, CYP3A4) tedavi amaçlı moleküllerin zararsız hale getirilmesinde önemli rol 
oynamaktadırlar. In silico olarak yapılan çalışmaya göre moleküllerin bu enzim aktivitelerini etkileme potansiyelleri Tablo 2'de sunulmuştur. Sentezlenen bileşiklerin, CYP2C9, CYP2D6 ve CYP3A4 enzimlerinin aktivitelerini etkileme potansiyeli tespit edilmemiştir. 4a, 4b ve 4c bileşikleri CYP1A2 ve CYP2C19 enzim aktivitelerini inhibe etme potansiyeline sahiptir.

Tablo 2. In Silico ADME Sonuçları

\begin{tabular}{|c|c|c|c|c|}
\hline ADME özellikleri & & $4 \mathbf{a}$ & 4b & $4 c$ \\
\hline \multirow{4}{*}{$\begin{array}{l}\text { Fizikokimyasal } \\
\text { özellikleri }\end{array}$} & Dönebilen bağ sayıs1 & 3 & 3 & 3 \\
\hline & H-bağ alıcı & 4 & 3 & 4 \\
\hline & H-bağ verici & 0 & 0 & 1 \\
\hline & TPSA $\AA^{2}$ & 43,60 & 43,60 & 52,83 \\
\hline \multirow{10}{*}{$\begin{array}{l}\text { Lipofiliklik } \\
\text { (Suda } \\
\text { çözünürlüğü) } \\
\text { Farmakokinetik }\end{array}$} & $\log S(\mathrm{ESOL})$ & $-2,76$ & $-3,19$ & $-2,65$ \\
\hline & MLogP & 2,76 & 2,89 & 2,06 \\
\hline & Absorpsiyon (\% ABS) & 93,95 & 93,95 & 90,77 \\
\hline & $\begin{array}{l}\text { Kan Beyin Bariyeri } \\
\text { geçme }\end{array}$ & Evet & Evet & Evet \\
\hline & $\begin{array}{l}\log K_{\mathrm{p}}(\text { Deri } \\
\text { geçirgenliği) }(\mathrm{cm} / \mathrm{s})\end{array}$ & $-6,37$ & $-6,09$ & $-6,53$ \\
\hline & CYP1A2 inhibitör & + & + & + \\
\hline & CYP2C19 inhibitör & + & + & + \\
\hline & CYP2C9 inhibitör & - & - & - \\
\hline & CYP2D6 inhibitör & - & - & - \\
\hline & CYP3A4 inhibitör & - & - & - \\
\hline
\end{tabular}

Sentezlenen $\mathbf{4 a}, \mathbf{4 b}$ ve $\mathbf{4 c}$ bileşikleri Lipinski'nin 5 kuralına göre incelendiğinde şu sonuçlar ortaya çıkar. Bileşiklerin molekül ağırlığı $500 \mathrm{~g} / \mathrm{mol}$ 'ün altındadır (yaklaşık 240 g/mol). Dönebilen bağ sayısı 3'tür. H-bağ alıcı sayısı 3-4, H-bağ verici sayısı 01 'dir. Kutuplaşmış yüzey alanı (TPSA $\AA^{2}$ ), 43,60-52,83 civarındadır. 4a, 4b ve $\mathbf{4 c}$ bileşikleri için MlogP değerleri sırasıyla, 2,76, 2,89 ve 2,06 şeklindedir. Lipinskinin 5 kuralında bu değer 5'in altında olmalıdır. Bileşiklerin sudaki çözünürlükleri oldukça yüksektir. Teorik olarak ince bağırsaktan emilim yüzdeleri de oldukça yüksek hesaplanmıştır. Görüldüğü üzere sentezlenen bileşiklerin teorik olarak hesaplanan ADME sonuçları Lipinskinin 5 kuralı ile uyum içerisindedir.

Program, ayrıca Tablo 3'de belirtilen kriterlerin esas alındığı bir oral biyoyararlanım radarı alanı sunar. Sonuçlar analiz edildiğinde, doymuşluk kriterini çok az geçtiği görülmekle beraber sentezlenen moleküller bu kriterlere uygunluk göstermektedir. 
Tablo 3. Moleküllerin İlaç Benzerliğinde Kimyasal Yapı ve Biyoyararlanım Radarı

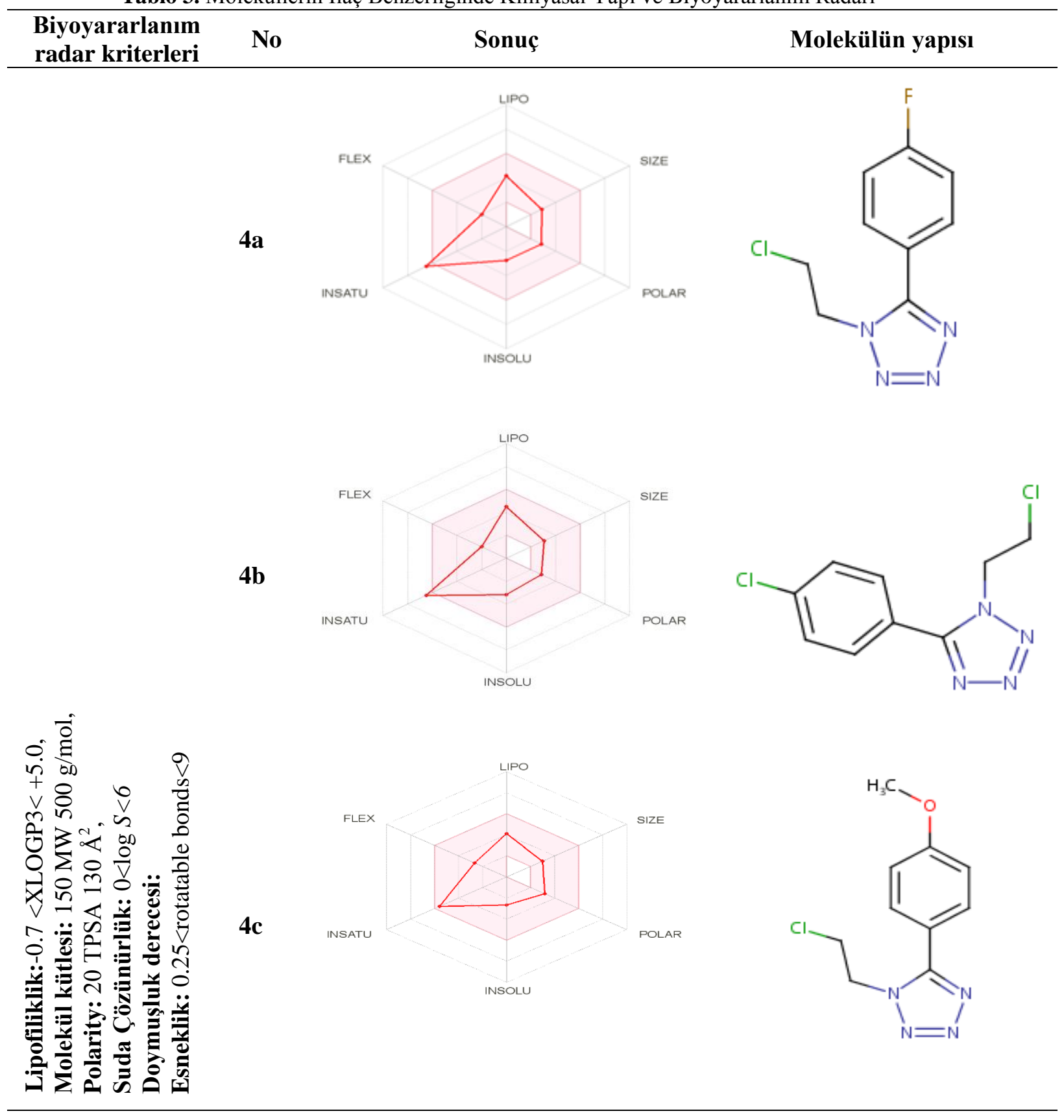

\section{Teşekkür}

Çalışma sürecinde verdikleri desteklerden dolayı Prof. Dr. Yılmaz Yıldırır, Prof. Dr. Ali Dişli, Doç. Dr. Şevki Adem ve Batuhan Yetim’e teşekkürlerimi sunarım.

\section{Kaynakça}

[1] J. D. Hepworth, "In Comprehensive Heterocyclic Chemistry" 1nd ed. vol.3, A. R. Katritzky, C. W. Rees, A. J. Boulton, A. McKillop, Ed. Pergamon: Oxford, 1984, pp. 799-810.

[2] V. A. Ostrovskii, M. S. Pevzner, T. P. Kofman, M. B. Shcherbinin, "Energetic 1,2,4-triazolesand tetrazoles synthesis, structure and properties" Targets Heterocycl. Syst., 3, 467-526, 1999.

[3] R. N. Butler, "In Comprehensive Heterocyclic Chemistry" 1nd ed. vol.3, A. R. Katritzky and C.W. Rees Ed. Pergamon: New York, 1984, pp. 791-799. 
[4] Y. Tamura, F. Watanabe, T. Nakatani, K. Yasui, M. Fuji, T. Komurasaki, K. Sugita, "Highly selective and orally active inhibitors of type IV collagenase (MMP-9 and MMP-2): $N$-sulfonylamino acid derivatives" J. Med. Chem., 41(4), 640-649, 1998.

[5] A. Abell, G. Foulds, "Synthesis of a cis-conformationally restricted peptide bond isostere and its application to the inhibition of the HIV-1 protease" J. Chem. Soc. Perkin Trans., 1(17), 2475-2482, 1997.

[6] O. A. Shemyakina, A. G. Mal'kina, A. I. Albanov, B. A. Trofimov, "Regio-and stereodirection of addition of tetrazole to $\alpha, \beta$-acetylenic $\gamma$-hydroxy nitrile: synthesis of 1-and 2-(Z)-(2-cyanoethenyl-1hydroxyalkyl) tetrazoles" Chem Heterocycl Comp., 47(4), 464-469, 2011.

[7] A. N. Chermahini, A. Ghaedi, A. Teimouri, F. Momenbeik, H.A. Dabbagh, "Density functional theory study of intermolecular interactions of cyclic tetrazole dimers" J. Mol. Struct., 867(1-3), 7884, 2008.

[8] H. Özkan, S. Yavuz, A. Dişli, Y. Yıldırır, L. Türker, "Synthesis of Novel 5-Aryl-1H-Tetrazoles" Heteroatom Chem., 18, 255-258, 2007.

[9] F.H. Dost, Der Blutspiegel; Kinetik der Konzentrationsabläufe in der Krieslaufflüssigkeit, Georg Thieme Verlag, Leipzig, 1953.

[10] F. H. Dost, Grundlagen der Pharmakokinetik, Georg Thieme Verlag, Leipzig, 1968.

[11] L. L. Ferreira and A. D. Andricopulo, "ADMET modeling approaches in drug discovery." Drug Discov. Today, 24, 1157-1165, 2019.

[12] Y. Suzuki, K. Moriyama, H. Togo, "Facile transformation of esters to nitriles" Tetrahedron, 67, 7956-7962, 2011.

[13] W. Y. Fang, H. L. Qin, "Cascade Process for Direct Transformation of Aldehydes (RCHO) to Nitriles (RCN) Using Inorganic Reagents $\mathrm{NH}_{2} \mathrm{OH} / \mathrm{Na}_{2} \mathrm{CO}_{3} / \mathrm{SO}_{2} \mathrm{~F}_{2}$ in DMSO” J Org Chem, 84, 5803-5812, 2019.

[14] V. R. Balaji, K. R. Prabhu, "Chemoselective Schmidt Reaction Mediated by Triflic Acid: Selective Synthesis of Nitriles from Aldehydes" J. Org. Chem., 77, 5364-5370, 2012.

[15] S. R. Paudel, X. B. Min, S. Acharya, D. B. Khadka, G. Yoon, K. M. Kim, S. H. Cheon, “Triple reuptake inhibitors: Design, synthesis and structure-activity relationship of benzylpiperidinetetrazoles" Bioorg. Med. Chem., 25 5278-5289, 2017.

[16] Z. P. Demko, K. B. Sharpless, "Preparation of 5-Substituted $1 H$-Tetrazoles from Nitriles in Water" J. Org. Chem., 66, 7945-7950, 2001.

[17] A. Daina, O. Michielin and V. Zoete "SwissADME: a free web tool to evaluate pharmacokinetics, drug-likeness and medicinal chemistry friendliness of small molecules." Sci. Rep., 7, 42717, 2017.

[18] Y. H. Zhao, M. H. Abraham, J. Le, A. Hersey, C. N. Luscombe, G. Beck, B. Sherborne and I. Cooper "Rate-limited steps of human oral absorption and QSAR studies." Pharm. Res., 19(10), 1446-1457, 2002.

[19] M. R. Grimmet, Diazoles, Triazoles, Tetrazoles and Their Benzo-analogues, Comprehensive Heterocyclic Chemistry, Pergamon Press: Oxford, 1979, pp. 357-410.

[20] J. Elguero, C. Marzin, The Tautomerism of Heterocycles, Advences in Heterocyclic Chemistry, Academic Pres: New York, 1976, pp. 287-291.

[21] G. B. Barlin, T. J. Batterham, "The proton magnetic resonance spectra of some diazoles, triazoles, and tetrazoles" J. Chem. Soc. B., 516-518, 1967.

[22] M. Begtrup, “13 C-NMR Spectra of Phenyl-substituted Azoles: a Conformational Study” Acta. Chem. Scand., 27, 3101-3110, 1973.

[23] S. Paudel, S. Acharya, G. Yoon, K.-M. Kim and S. H. Cheon "Exploration of substituted arylpiperazine-tetrazoles as promising dual norepinephrine and dopamine reuptake inhibitors." Bioorg. Med. Chem., 24(21), 5546-5555, 2016.

[24] S. Paudel, S. Acharya, G. Yoon, K.-M. Kim and S. H. Cheon "Design, synthesis and in vitro activity of 1, 4-disubstituted piperazines and piperidines as triple reuptake inhibitors." Bioorg. Med. Chem., 25(7), 2266-2276, 2017.

[25] C. A. Lipinski, F. Lombardo, B. W. Dominy and P. J. Feeney "Experimental and computational approaches to estimate solubility and permeability in drug discovery and development settings." $A d v$. Drug Deliv. Rev., 23(1-3), 3-25, 1997.

[26] A. K. Ghose, V. N. Viswanadhan and J. J. Wendoloski "A knowledge-based approach in designing combinatorial or medicinal chemistry libraries for drug discovery. 1. A qualitative and quantitative characterization of known drug databases." J. Comb. Chem., 1(1), 55-68, 1999.

[27] W. J. Egan, K. M. Merz and J. J. Baldwin "Prediction of drug absorption using multivariate statistics." J. Med. Chem., 43(21), 3867-3877, 2000. 
[28] I. Muegge, S. L. Heald and D. Brittelli "Simple selection criteria for drug-like chemical matter." J. Med. Chem., 44(12), 1841-1846, 2001.

[29] D. F. Veber, S. R. Johnson, H. Y. Cheng, B. R. Smith, K. W. Ward and K. D. Kopple "Molecular properties that influence the oral bioavailability of drug candidates." J. Med. Chem., 45(12), 26152623, 2002.

[30] P. F. Hollenberg, "Characteristics and common properties of inhibitors, inducers, and activators of CYP enzymes." Drug Metab. Rev., 34(1-2), 17-35, 2002.

[31] J. Kirchmair, A. H. Göller, D. Lang, J. Kunze, B. Testa, I. D. Wilson, R. C. Glen and G. Schneider "Predicting drug metabolism: experiment and/or computation?" Nat. Rev. Drug Discov., 14(6), 387, 2015. 